\title{
Os Mecanismos da Paixão: o Hipólito de Eurípides e o Elogio de Helena de Górgias
}

\author{
Fernando Crespim Zorrer Silva \\ Universidade Federal do Espírito Santo (UFES) \\ fernando.zorrer@gmail.com
}

Pensadores como Eurípides e Górgias dissertaram sobre a Filosofia, a paixão, os deuses e tantos outros assuntos. É importante, aqui, demonstrar como avaliaram os atos dos homens a partir do comportamento de personagens femininos como Fedra e Helena. Deve-se, ainda, apontar alguns pontos de contato de suas obras, ressaltando como é possível terem alcançado, mesmo que cada um pertença a uma esfera diferente do conhecimento, especulações muito próximas.

Palavras-chave Helena. Fedra. Hipólito. Eurípides. Górgias.
Keywords

Helen. Phaedra. Hippolytus. Euripides.

Gorgias. 
Contrapor dois pensadores de áreas do conhecimento distintas é um ato que gera inúmeras implicações epistemológicas, no entanto, quando participaram de uma mesma sociedade e viveram em um mesmo período histórico, pode proporcionar reflexões sobre como o homem articula as suas ideias e revelar como analisar de modo mais adequado um determinado contexto cultural. Aqui, como alvo de reflexão para ampliar o debate desse tipo de investigação, propõe-se examinar a tragédia Hipólito de Eurípides e dialogar com o texto o Elogio de Helena do filósofo Górgias de Leontino. Há muitos tópicos os quais podem ser relacionados, uma vez que tais obras sugerem, como se demonstrará mais adiante, uma intensa comunicação, pois ambos os autores apresentam e examinam questões similares. Não se pretende, aqui, realizar um trabalho exaustivo e completo, mas são analisados alguns tópicos das referidas obras.

Em um primeiro momento, é necessário situar os autores analisados. Eurípides destaca-se por ser um dramaturgo que apresenta um teatro mais flexível, aberto às surpresas, aos debates e às análises psicológicas (Romilly, 1986). Neste caso, é conveniente ser chamado de moderno em relação aos seus predecessores (Ésquilo e Sófocles), pois aquele tragediógrafo descobriu, inovou e até escandalizou um pouco com as suas tragédias (). Com efeito, naquele momento histórico-cultural, os problemas e os questionamentos sustentados pela nova Filosofia que emergia naquela época não passaram despercebidos por esse dramaturgo. Neste período, descobertas importantes surgiam no plano da Medicina, da Dialética, da Retórica que, na verdade, significavam novos modos de pensamento. Esse conjunto de novidades que o conhecimento humano arti- culava foi debatido por diversos pensadores, como Sócrates e Hipócrates, por exemplo, mais havia ainda um grupo de pensadores, os sofistas que discutiam os mais distintos campos do saber, além de colocarem, em dúvida, elementos que fundamentavam a cidade como deuses e mitos, enfim, a própria tradição era questionada.

Além disso, pelos fragmentos encontrados, a tragédia também foi assunto de discussão pelos filósofos, como é o caso de Górgias de Leontino, que chegou a Atenas em 427 e curiosamente a peça Hipólito, de Eurípides, foi representada em 428. Ambos eram contemporâneos e esse fato corrobora a explicação de que eles partilhavam ideias e inquietações sobre o universo social no qual estavam inseridos, a saber, a participação dos deuses na vida humana e o poder da palavra nas decisões desses últimos. Em termos históricos, há o registro de declarações de Górgias a respeito do gênero trágico, como consta nas Questões convivais, de Plutarco, em que teria afirmado que a tragédia Sete Contra Tebas, de Ésquilo, está repleta do deus Ares. Trata-se de uma interpretação sintética a respeito de uma peça; apesar de ser uma declaração pontual, como é um fragmento isolado e dentro de outra obra, isto é, consta do texto de Plutarco, esse pensador poderia ter retirado tal afirmação a partir de uma obra mais extensa de Górgias. Assim, trata-se de uma opinião que demonstra a preocupação desse filósofo com uma instância cultural significativa do período clássico.

Apesar da escassez de textos, há um no qual se observa a análise de Górgias sobre o teatro. Trata-se do fragmento 23 , que, de acordo com Robert Wardy (1996, p. 36), aquele sofista julga que a 
[...] tragédia, para ter o seu efeito característico, deve produzir uma ilusão teatral a fim de cativar a audiência tanto no plano intelectual como no emocional; ainda, os indivíduos necessitam reagir como se acontecesse realmente o que sucede no palco, como se eles desfrutassem da experiência trágica. Para que isso ocorra de modo eficaz, é necessário que o dramaturgo produza um mundo imaginário, mas o público também deve imbui-lo de realidade, por meio da 'suspensão da descrença'. Deste modo, o espetáculo trágico requer um conluio na simulação [...] nós devemos conceber a experiência teatral como tipo de uma ilusão contratual, que depende da cooperação entre a tragédia enganadora e a receptiva audiência iludida.

Através da análise desse fragmento, sobretudo, destaca-se a capacidade de percepção do filósofo no que concerne a uma obra literária não só prestando atenção no texto dramático, mas também na representação teatral e na importância do público em todo o processo.

Considerando esse contexto cultural, observa-se que o próprio Eurípides já foi considerado um sofista pela crítica literária, isto é, como aquele que procurou dissolver as crenças tradicionais das quais o dramaturgo era um adversário (Rivier, 1975). Na sua biografia, há registros de que tenha tido como mestres alguns sofistas importantes como foi o caso de Pródico. Também é significativo o fato de que Aristófanes tê-lo inserido no mesmo grupo desses pensadores em diferentes comédias, como nas Nuvens, ao lado de Sócrates.

Cada uma dessas obras, Hipólito e Elogio de Helena, pertence a um gênero distinto do conhecimento humano bem como apresenta intrínsecas particularidades. Mais do que nunca, em ambos os textos, o mito é objeto de reflexão. Na peça de Eurípides, descrevem-se os resultados da paixão de Fedra, esposa de Te- seu, justamente pelo seu enteado, Hipólito, até o seu término. Já no texto de Górgias, há um exame sobre um ato já consumado. Além disso, esse filósofo trata das possibilidades que fizeram com que a personagem Helena saísse de sua casa e acompanhasse Páris até Tróia; ainda, o motivo para isso seria a sua paixão de forte cunho sexual - na verdade, Helena se constituiria em um arquétipo desse sentimento não só para os gregos mas também para a posteridade (Wardy, 1996). Nesse sentido, observam-se muitas referências a Helena na Literatura Grega, por exemplo, na llíada, quando acompanha Páris, ao passo que Fedra não se aproxima do ser amado, nem lhe dirige uma palavra ou toca-lhe o corpo. Helena não morre - pelo menos, é o que a tradição transmitiu - , segundo o próprio Eurípides nas tragédias Helena, Troianas, Andrômaca, Hécuba (ver os versos 265-266; 943-952), e Orestes (nessa última, esteve prestes a morrer, contudo foi salva pelo deus Apolo) e também no drama satírico Ciclope, versos 179-187, no qual Helena é criticada, pois é aquela que aprecia a troca de esposo. É preciso que se ressalte que Górgias segue a versão tradicional do mito de Helena, conforme também o faz Homero (Gagarin, 2002). No caso de Fedra, essa personagem se suicida com uma corda no pescoço, ao julgar que não tinha meios de se salvar, visto que Hipólito foi informado do desejo da rainha através da aia, além de ter considerado que o enteado havia desprezado a sua dor:

Contudo tornar-me-ei, quando morrer, funesta ao outro, para que aprenda que, com os meus males, não seja orgulhoso. E partilhando comigo nesta doença em comum, ele aprenderá a ser prudente (Eurípides, 1950, v. 728731). 
Cada um dos pensadores, Eurípides e Górgias, não julga a paixão como algo que necessita ser evitado, criticado. Górgias assume explicitamente, no início de seu texto, que refutará aqueles que detrataram Helena e que pretende libertá-la da má reputação que lhe foi outorgada. No caso de Hipólito, não há uma declaração taxativa a respeito do intento amoroso da rainha, mas sim é exposta a situação dessa personagem, da sua realidade psíquica, da gravidade do ato de uma mulher que se apaixona pelo enteado e todas as implicações que tal ação gera. Em termos de contraponto, a Fedra de Eurípides é bem distinta da forma como é apresentada por Sêneca, em sua tragédia Fedra, pois a personagem homônima possui um comportamento que deve ser evitado e criticado, visto que não seguiu os preceitos estóicos, isto é, não conteve a sua paixão (Evans, 1950).

Ainda sobre Fedra, tudo não passa das especulações de um desejo que não é consumado, de um adultério que realmente não se efetiva, que permanece no plano dos pensamentos e de um mal-entendido provocado pela aia tudo isso pertence à esfera do proibido, isto é, a rainha não poderia pensar em outro homem a não ser em seu marido, Teseu, que somente aparece quando a sua esposa já está morta. No prólogo da peça, a deusa Afrodite apresenta, em linhas gerais, o que sucederá ao longo do drama, mas não comenta a importância da nutriz no desenvolvimento dos acontecimentos; eis um recurso literário que despista a atenção de quem está assistindo ou lendo essa tragédia. Eurípides consegue, assim, salientar as características da culpa feminina, não envolvendo um casal de amantes - no sentido romântico do termo - , além de acrescentar que o intento amoroso da rainha carrega todos os constrangimentos e todas as punições psíquicas, visto que a personagem está em um estado psíquico e biológico que se encontra em declínio (não come há três dias, v. 135 ss, e, de um momento para outro, tem delírios, conforme os versos 208-211, 215-222, 228-231, do primeiro episódio). Esse quadro psíquico contribui para que a filha de Pasifae faça escolhas inadequadas em momentos decisivos de sua vida e essas contribuam na morte do filho de Teseu bem como na sua própria desdita.

Já o termo phármakon (droga medicinal; operação de magia, como canto, encantamento, fórmula; meio, expediente) que aparece no texto trágico, ainda no primeiro episódio, merece destaque, aqui, porque é decisivo no andamento da trama da peça de Eurípides. Tal vocábulo representa um dos elementos fundamentais para o encaminhamento da tragédia; trata-se do momento no qual a aia de Fedra engana-a, afirmando que possuía recursos para curar o mal da rainha (Goff, 1996); é um expediente para trocar a atenção da esposa de Teseu, buscando uma outra saída para a situação na qual Fedra se encontra. Reexplicando, de um outro modo, houve um momento no qual havia indicativos de que a paixão de Fedra seria interrompida e de que essa personagem não teria o desfecho trágico, como foi anunciado por Cípris no prólogo; entretanto, no final do primeiro episódio, a nutriz, após ter realizado um longo discurso, declara que possui em casa "filtros que apaziguam / a paixão", (Eurípides, 1995, v. 509-510), que, ao contrário de apaziguarem o desejo amoroso da rainha, representam referências dissimuladas tanto para a persuasão como para a sedução que a aia tentará utilizar sobre o próprio Hipólito (Goff, 1996). Além disso, Barbara Goff também sugere que ambas as obras abordam a ques- 
tão do desejo humano, do phármakon como 'metáfora para a linguagem' (Ibid.), da persuasão e da sedução. No texto do dramaturgo, phármakos remete à sedução e à simulação do desejo que está subtendido. De acordo com essa interpretação, Charles P. Segal pondera quanto à essa passagem que o dramaturgo concilia a sua expressividade lírica com a teorização contemporânea, quando ressalta o poder da linguagem tanto para evocar como para manipular os sentimentos, como também é sugerido no texto de Górgias (Segal, 1993), quando esse filósofo aproxima a força do discurso com o poder dos medicamentos (phármakon) que conseguem, ambos, alterar a saúde do corpo.

Se fizermos novamente uma reflexão sobre as personagens, veremos que as ações de $\mathrm{He}-$ lena assim como as de Fedra constituem em um assunto importante que é alvo da especulação desses pensadores e a partir de seus atos surgem novos tópicos. Neste caso, não há um outro foco subjacente a todo esse processo, como fez Sócrates na sua obra Helena, na qual é Teseu quem está sendo aclamado como um importante representante mitológico (Wardy, 1996). É interessante observar que até mesmo Sócrates reprova Górgias por não ter escrito um encômio, mas sim uma defesa da filha de Leda. A ação humana é o verdadeiro ponto-chave de investigação e, mais do que nunca, ambos os escritores revelam (Eurípides e Górgias) alguns aspectos que não são divergentes, pois compreendem que o agir humano é influenciado por diversos tipos de agenciamentos (a sociedade, a família, a capacidade de compreender a realidade).

$\mathrm{Na}$ tragédia Hipólito, há muitas explicações apresentadas pelos personagens para os atos dos mortais; praticamente, todos eles se ma- nifestam sobre o assunto. É decisiva a atuação da aia que tenta convencer a sua senhora para não resistir ao ímpeto e à força de Afrodite, visto que a rainha está amando devido à interferência dessa divindade. Além disso, a serva emprega uma questão retórica ao indagar se Fedra não estaria cometendo a hybris em querer ser mais forte que os deuses:

Mas, cara filha, cessa os males da mente, cessa a tua insolência; pois isto não é mais do que uma insolência ao querer ser mais forte do que os nomes. Ousa amar: isso foi desejado por um deus. Eurípides,1995, v. 473-476).

Neste sentido, tais versos podem ser aproximados com a argumentação de Górgias que afirmou "A divindade é mais poderosa que o homem, tanto na força como na sabedoria e em tudo o mais" (Górgias, 1993, p. 6). Ambos os pensadores, assim, examinam os atos das figuras femininas e procuram estabelecer o motivo de suas ações. Há uma de que o divino está presente nas ações dos personagens e a questão é avaliar o quanto os deuses intercedem no mundo dos mortais.

Ainda, no Elogio de Helena, de Górgias, esse texto é organizado de modo didático, pois é apresentada uma série de possibilidades que explicariam o ato de Helena, isto é, por qual motivo teria essa personagem abandonado a família e se unido a Páris. Uma das explicações para esse ato consiste na intervenção de uma divindade, neste caso, Eros, cujo pai, segundo a tradição, pode ser algum deus, como Urano, Ares, Zéfiro. De fato, o texto de Górgias é o fundador de muitas discussões que giram em torno da liberdade e do determinismo (Kenny, 2004). Eurípides estava igualmente tratando de semelhantes questões em Hipólito bem como em outras tragédias, uma vez que não só co- 
menta a intervenção de divindades nas ações dos homens como também sugere a habilidade retórica da aia de trocar de opinião, de um momento para o outro, de enganar a própria rainha que, na peça, demonstra possuir uma elevada capacidade para a reflexão. Neste sentido, quando a deusa Ártemis proclama a Teseu, no epílogo, que "Sem querer o mataste, e aos homens / é provável que errem se os deuses assim o ordenam", (Eurípides, 1995, v. 1433-1434), o dramaturgo, aqui, não está simplesmente colocando um ponto final na discussão quanto à intervenção dos deuses. $\mathrm{Na}$ verdade, não são esses realmente os responsáveis pelas ações humanas, ou, em outra linha de análise, Eurípides está problematizando ainda mais a complexidade desse assunto. Com essa última afirmação da divindade, os erros humanos se tornaram tão simples, praticamente nulos, porque agora podem ser esquecidos, perdoados e nem podem ser questionados, ou seja, em tudo um deus se oculta, invadindo os atos dos mortais. Avaliando ainda mais o assunto, observa-se que, no fundo, o dramaturgo nos leva ao relativismo ou a uma sofisticada explicação de cada ato, acentuando que a escolha do responsável por uma ação dependerá, de certo modo, do ponto de vista de sua abordagem. No texto de Górgias, há algo similar, quando ressalta, por exemplo, o poder do logos e de outros elementos que poderiam estar presentes ao mesmo tempo nos atos de Helena.

$\mathrm{Na}$ verdade, além da presença de um elemento divino que justificaria os atos dos mortais, Górgias ainda menciona a ação individual de um mortal, sem que esse mantivesse uma relação direta com um deus, que, a partir do discurso (logos) e da força, teria obtido Helena. Não é somente esse motivo que explicaria a ação singular de Helena que é objeto aqui de investigação. Tais implicações também ocorrem na tragédia de Eurípides como já foi mencionado anteriormente. A aia de Fedra é considerada como alguém que articula o discurso, assemelhando-se, por seus atos, à prática dos sofistas, visto que altera os argumentos, de acordo com as exigências das circunstâncias para obter êxito no seu intento (Knox, 1986).

Se formos mais adiante nas avaliações, o filósofo sofista apresentou um suposto 'esboço' de teoria da ação dramática, que, de certo modo, aparece no Hipólito de Eurípides. Poder-se-ia ainda mais ampliar a discussão se fosse contraposto com as tragédias desse último autor, uma vez que ele coloca, em discussão, alguns temas que estão presentes no discurso de Górgias. Assim, de acordo com essa possibilidade, poderia se indagar, aqui, de modo retórico, se o referido sofista não poderia ter composto um 'Elogio de Fedra', se apresentasse boa parte dos argumentos que empregou para defender Helena para a heroína de Eurípides. Aqui, o dramaturgo, fundamentalmente, não apresentou uma 'Defesa de Fedra'; explorou, sim, a situação dramática sem enfatizar que a esposa de Teseu teria cometido um grave erro. Górgias de Leontino poderia ter apresentado os motivos pelos quais Fedra agiu, como, por exemplo, o suicídio e a falsa incriminação de abuso por Hipólito. Neste caso, incluiria alguns elementos como a presença de Afrodite e o poder dos deuses, o poder do logos e outros motivos poderiam ser adicionados como o temor da descoberta da paixão da rainha pelo enteado, e, assim por diante.

Em relação às intervenções divinas na ação de Helena, de acordo com Górgias, além de Afrodite, é mencionado o deus Eros (v. 15-19), 
ao contrário da tragédia de Eurípides, na qual há muitos deuses (Afrodite e Ártemis aparecem atuando na tragédia em momentos estratégicos, pois suas falas fazem parte tanto do prólogo como do êxodo, ao passo que outros deuses são mencionados, como Zeus, Apolo e até outras divindades que não participam do Olimpo, como o deus Pã) que parecem estar intervindo nos atos humanos diretamente ou indiretamente. No texto sobre Helena, ali só se encontram referências a ela, a seus pais e a sua beleza; já os seguidores não são nomeados; outros detalhes de quem foi a Tróia, igualmente, não são apresentados; se Páris é mencionado somente no final do texto, vale destacar que há um preparativo para a revelação do seu nome, visto que inicialmente é considerado um bárbaro que teria cometido um ato ultrajante; neste caso, trata-se de um recurso empregado em outras obras com uma argumentação generalizada (Innes, 1991). Além disso, o deus Eros é responsável pelo ato de acompanhar Páris.

Também é interessante observar que Fedra, em nenhuma ocasião, chama Hipólito pelo seu nome, somente empregando pronomes, substantivos e epítetos, como no verso 731 : "Quem quer que este seja, o filho da amazona ...", (Eurípides, 1995, v. 351). Não se trata de uma coincidência quando o personagem não é nomeado, mas de um recurso sofisticado para reforçar a dramaticidade da tragédia, fazendo com que os ouvintes ou os leitores participem mais do processo de interpretação e de interação. Imagina-se a tensão do público na representação teatral da peça Hipólito, uma vez que aquele sabe que Afrodite já apareceu e anunciou o que ocorrerá no desenrolar da trama; há, de fato, uma defasagem entre o que ocorre na peça e o conhecimento que o públi- co possui acerca da tradição mítica bem como a própria primeira versão teatral de Eurípides, pois a aia de Fedra não é mencionada, como já se apontou.

Dentro da perspectiva que ambos os escritores (Eurípides e Górgias) salientam, ainda sobre Eros, uma das questões a se examinar é como surgiu a paixão e como cada um dos textos apresenta o tema do olhar relacionado à beleza. Górgias indaga o que há de errado se o olhar de Helena afeiçoou-se ao corpo de Alexandre. Já no prólogo da peça de Eurípides, pronunciado por Afrodite, Fedra é citada como aquela que viu Hipólito e que se apaixonou por ele, "Fedra, viu-o e ficou possuída em seu coração", (Eurípides, 1995, v. 27). Consistiria em uma das explicações para essa paixão a ideia de que essa nasce através do olhar sobre o objeto de desejo. É importante observar que, posteriormente na tragédia, quando o coro proclama: Eros, Eros, que, pelos meus olhos, destilas o desejo, introduzindo um doce prazer na alma dos que o combatem me surjas como algo funesto. Nem venhas desmedido (Eurípides, 1995, v. 525-529). Assim, mais uma vez, o texto dramático estaria, pois, a ressaltar o poder desse sentido bem como enfatizando o processo pelo qual Fedra se apaixonou de Hipólito e que, em verdade, não se trata de algo que está especificamente relacionado à rainha mas também é experimentado e atestado pelo grupo de mulheres que formam o coro.

Após o exame de algumas questões entre as duas obras do período clássico grego, observam-se pontos de contato entre as suas ideias. Na realidade, cada pensador construiu o seu pensamento tendo alvos diferentes, porém há traços em comum. Cada um dispôs de diversos elementos e os articulou dentro de sua área respectiva do conhecimento. 
Eurípides construiu a tragédia de tal modo que não se pode apontar claramente se a rainha ou Hipólito são, plenamente, culpados por seus atos. No caso de Górgias, a articulação segue por um outro caminho, pois o filósofo assume uma posição contrária ao que tem sido realizado pela tradição a respeito da figura de Helena, pois essa é acusada das mais diversas formas, conforme se observam nas obras de Homero, Ésquilo e outros pensadores. Mesmo que o seu texto pareça que não se deva levar a sério, como o próprio filósofo comenta no final, tal afirmação nada mais é que um sofisticado recurso sofístico para afirmar tudo o que apresentou. Em ambos os autores, Eurípides e Górgias, se observam muitos agenciamentos que atuam no agir humano, como a presença dos deuses, o emprego persuasivo da linguagem, enfim, há uma gama de possibilidades que estão interferindo na ação humana em todo o seu desenvolvimento.

\section{Referências}

EURÍPIDES. Children of Heracles. Hippolytus. Andromache. Hecuba. Trad. David Kovacs. London: Harvard University Press, 1995b. v. 2.

EVANS, Elizabeth C. A stoic aspect of senecan drama: portraiture. Transactions and Proceedings of the American Philological Associations, v. 81, p. 169-184, 1950.

GAGARIN, Michael. Antiphon the Athenian: Oratory, Law and Justice in the Age of the Sophists. Austin: University of Texas Press, 2002.
GOFF, E. Barbara. The noose of words: readings of desire, violence \& language in Euripides' Hippolytos. Cambridge: Cambridge University Press, 1996.

GÓRGIAS. Fragmentos e testemunhos. (sofista grego, século $\mathrm{V}$ a. C.). Tradução, comentário e notas de Manuel José de Sousa Barbosa e Inês Luisa de Ornellas e Castro. Lisboa: Colibri, 1993 (Mare Nostrum).

INNES, D. C. Gorgias, Antiphon and Sophistopolis, Argumentation, v. 5, p. 221-27, 1991.

KENNY, Anthony. A new History of Western Philosophy. Ancient Philosophy. v. 1. Oxford: Clarendon Press, 2004.

KNOX, Bernard. World and action: essays on the Ancient Theater. Baltimore: The Johns Hopkins University Press, 1986.

RIVIER, André. Essai sur le tragique d'Euripide. 2. ed. Paris: Diffusion de Boccard, 1975.

ROMILLY, Jacqueline de. La modernité d'Euripide. Paris: Press Universitaires de France, 1986.

SEGAL, Charles P. Euripides and the Poetics of Sorrow: Art, Gender and Commemoration in Alcestis, Hippolytus and Hecuba. Durham/ London: Duke University Press, 1993.

WARDY, Robert. The birth of Rhetoric: Gorgias, Plato and their successors. London; New York: Routedge: 1996. (Issues in Ancient Philosophy). 
Recebido: 25/06/2017

Aprovado: 13/02/2018 